
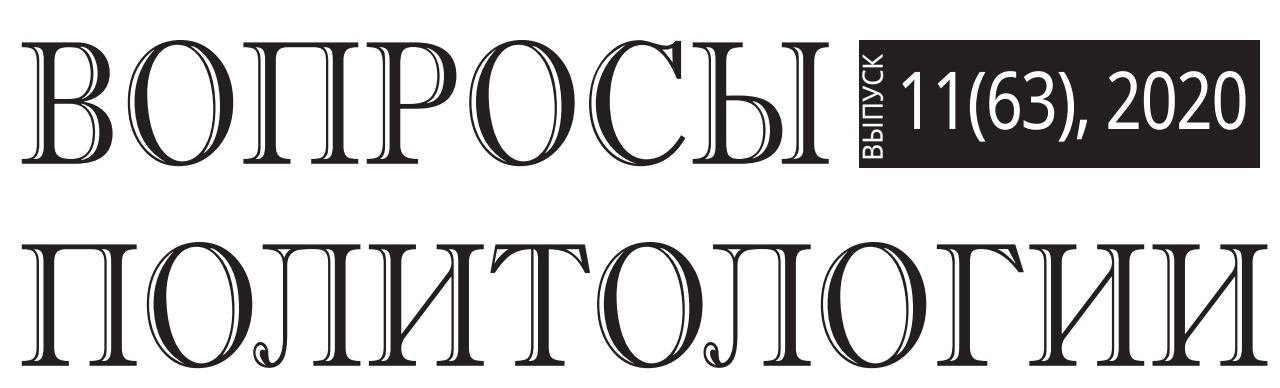

Научный журнал

Журнал «Вопросы политологии» включен

в Перечень рецензируемых научных изданий

BAK Министерства образования и науки РФ по политическим наукам, в которых должны быть опубликованы основные научные результаты на соискание ученой степени кандидата наук,

на соискание ученой степени доктора наук

Журнал включен в Перечень научных изданий рекомендованных ВАК Республики Узбекистан для публикации основных научных результатов диссертаций по политическим и философским наукам 
Председатель Редакционного Совета - ПЛАТОНОВ В.М.,

К.ю.н., заведующий кафедрой политического анализа и управления РУДН, Председатель Московской городской Думы (1994-2014 гг.)

\section{Редакционный Совет}

\section{АСТВАЦАТУРОВА}

Майя Арташесовна

БОЖАНОВ

Владимир Александрович

ВЕДРИН

Оливье

ДОНАЙ

Лукаш

ЖИЛЬЦОВ

Сергей Сергеевич

ИРХИН

Юрий Васильевич

\section{КАРАДЖЕ}

Татьяна Васильевна

КЕТЦЯН

Григор Ваникович

\section{КОВАЛЕНКО}

Валерий Иванович

КРИВОКАПИЧ

Борис

МЕДВЕДЕВ

Николай Павлович

МИХАЙЛОВ

Вячеслав Александрович

\section{НАСИМОВА}

Гульнара Орленбаевна

\section{НИСНЕВИЧ}

Юлий Анатольевич

Шукритдин Ильясович

\section{ПЛЯЙС}

Яков Андреевич

ПРЯХИН

Владимир Федорович

ПУСЬКО

Виталий Станиславович

\section{ХОПЁРСКАЯ}

Лариса Львовна

\section{ПАХРУТДИНОВ}

д.п.н., профессор, директор Центра этнополитических исследований, профессор кафедры креативноинновационного управления и права Пятигорского государственного университета, координатор Сети этнологического мониторинга и раннего предупреждения конфликтов в СКФО (Россия, г. Пятигорск)

д.и.н., профессор, зав. кафедрой мировой и отечественной культуры Белорусского Национального технического университета (Белоруссия, г. Минск)

профессор, главный редактор русской версии французского журнала «Национальная оборона» (Revue Défense Nationale), спикер Европейской комиссии, редактор франко-германского журнала по вопросам внешней политики «European Union Foreign Affairs Journal» и ректор «Континентального университета в Киеве» (Франция, г. Париж)

Д.п.н., профессор факультета политологии и журналистики Департамента международных отношений Университета им. Адама Мицкевича в Познани (Польша, г. Познань)

д.п.н., заведующий кафедрой политологии и политической философии Дипломатической академии МИД РФ (Россия, г. Москва)

д.ф.н., профессор кафедры политологии и политического управления РАНХ и ГС при Президенте РФ (Россия, г. Москва)

д.ф.н., заведующая кафедрой политологии и социологии МПГУ (Россия, г. Москва)

к.П.Н., заместитель Главного редактора журнала, Председатель Попечительского Совета научного журнала «Вопросы политологии» (Россия, г. Москва) д.ф.н., зав. кафедрой российской политики МГУ им. М.В. Ломоносова (Россия, г. Москва)

д.ю.н., профессор факультета бизнеса и права Унион Никола Тесла университета (Сербия, Белград)

д.п.н., профессор кафедры анализа и управления Российского университета дружбы народов, главный редактор журнала (Россия, г. Москва) д.и.н., зав. кафедрой национальных и федеративных отношений РАНХ и ГС при Президенте РФ (Россия, г. Москва)

д.п.н., профессор, зав. кафедрой политологии факультета философии и политологии Казахского Национального университета им. Аль-Фараби (Казахстан, г. Алматы) д.п.н., профессор Национального исследовательского университета «Высшая школа экономики» (Россия, г. Москва)

д.п.н., профессор, заведующий кафедрой основы духовности Института переподготовки и повышения квалификации руководителей и специалистов системь народного образования имени А. Авлони (Узбекистан, г. Ташкент)

д.и.н., д.п.н., профессор Финансового университета при Правительстве РФ (Россия, г. Москва)

д.п.н., профессор кафедры зарубежного регионоведения и внешней политики РГГУ (Россия, г. Москва)

д.ф.н., профессор кафедры гуманитарных дисциплин ВА РВСН им. Петра Великого (Россия, г. Москва)

д.п.н., профессор кафедры международных отношений Киргизско-Российского славянского университета, (Киргизия, г. Бишкек)

\section{Редакционная коллегия}

Главный редактор - МЕДВЕДЕВ Н.П., д.П.н., профессор

Абрамова О.Д. (д.п.н.)

Насимова Г.О. (д.п.н.)

Кетцян Г.В. (к.п.н. - зам. гл. редактора)
ISSN 2225-8922

ЖУРНАЛ ВКЛЮЧЕН В ПЕРЕЧЕНЬ ВАК РФ

\section{УЧРЕЖДЕН}

ООО «Издательство «Наука сегодня»

Журнал зарегистрирован

Федеральной службой по надзору в сфере массовых коммуникаций, связи и охраны культурного наследия

\section{Рег. № ПИ № ФС77-46176} от 12 августа 2011 г.

Журнал издается ежемесячно

Журнал включен в базу РИНЦ (Российский индекс научного цитирования)

Включен в каталог Ulrich's Periodicals Directory

Пятилетний импакт-фактор: 1,489.

Адрес редакции: 115598 , г. Москва, ул. Загорьевская, д. 10, корп. 4, цокольный этаж, помещение I, комната 7-1, офис 4 Тел.: (910) 463-53-42

Интернет-ресурс: www.voprospolitolog.ru E-mail: voprospolitolog@yandex.ru

Мнение авторов может не совпадать с мнением редакции. При перепечатке ссылка на журнал обязательна.

Научные статьи, публикуемые в журнале подлежат обязательному рецензированию.

Ответственный редактор Шкурина С.С.

Перевод

Чернышова Е.В.

Компьютерная верстка Анциферова А.С.

Подписано в печать 26.11.2020

Формат 60×84/8. Объем 24,3.

Печать офсетная.

Тираж - 1000 экз.

(1-й завод - 500 экз.) Заказ № 0000.

Отпечатано в типографии PrintUP 117105 , г. Москва, Нагорный проезд, 12, корп. 1 Тел.: +7 (495) 925-00-06 
ISSN 2225-8922 (print)

12 выпусков в год и

4 выпуска в год переводной (англ.) версии

Языки: русский, английский

http://voprospolitolog

Входит в перечень рецензируемых научных изданий ВАК РФ Включен в каталог периодических изданий Ульрих

(Ulrich's Periodicals Directory: http://www.ulrichsweb.com)

Материалы журнала размещаются на платформе РИНЦ

Российской научной электронной библиотеки, Electronic Journals Library Cyberleninka

Подписной индекс издания в каталоге агентства Роспечать 70035

\section{Цели и тематика}

Журнал ВОПРОСЫ ПОЛИТОЛОГИИ - периодическое международное рецензируемое научное издание в области политических исследований. Журнал является международным как по составу редакционного совета и редколлегии, так и по авторам и тематике публикаций.

Научный журнал издается с 2011 года в издательстве «Наука сегодня». С 2016 года издается переводная (англ.) версия журнала. С момента своего создания, журнал ориентировался на высокие научные и этические стандарта и сегодня является одним из ведущих политологических журналов России.

Цель журнала - способствовать научному обмену и сотрудничеству между российскими и зарубежными политологами.

Журнал предназначен для публикации результатов фундаментальных и прикладных научных исследований. Тематическая направленность журнала отражается в следующих постоянных рубриках: «История и философия политики», «Политические институты, процессы и технологии», «Политическая регионалистика и этнополитика», «Политическая культура и идеологии», «Политические проблемы международных отношений и глобализации».

Формат публикаций: научные статьи, обзорные научные материалы, материалы круглых столов, научные рецензии, научные сообщения, посвященные исследовательским проблемам в сфере политики и политологии.

В своей деятельности редакционный совет и редколлегия журнала руководствуется принципами, определяемыми ВАК России для научных журналов, в том числе: наличие института рецензирования для экспертной оценки качества научных статей; информационная открытость издания; наличие и соблюдение правил и этических стандартов представления рукописей авторами.

Целевой аудиторией журнала являются российские и зарубежные специалисты-политологи, а также аспиранты и магистры, обучающиеся по направлениям политология, государственное и муниципальное управление и международные отношения.

Журнал строго придерживается международных стандартов публикационной этики, обозначенных в документе СОРЕ (Committee on Publication Ethics) http://publicationethics.org

Полные сведения о журнале и его редакционной политике, требования о подготовке и публикации статей, архив (выпуски c 2011 года) и дополнительная информация размещена на сайте: http://voprospolitolog.ru

Электронный адрес: voprospolitolog@yandex.ru

ISSN 2225-8922 (print)

12 issues a year plus 4 issues a year of the translated (eng.) version Languages: Russian and English http://voprospolitolog

Included in the list of peer-reviewed scientific publications of the Higher Attestation Commission of the Russian Federation Included in the Ulrich's Periodicals Directory Materials of the journal are placed on the RSCI platform of the Russian scientific electronic library - Electronic Journals Library Cyberleninka Subscription index of the journal in the Rospechat Agency catalogue is: 70035

\section{Objectives and themes}

Academic journal "Political Science Issues" is an international peer-reviewed scientific periodical in the field of political studies. The journal has an international character because of the composition of its Editorial Board, its editors, its contributing authors and topics of its publications.

The scientific journal is published since 2011 at the "Publishing House "Science Today". Translated (eng.) version of the journal is published since 2016. Since its inception, the journal was guided by high scientific and ethical standards and today it is one of the leading political science journals in Russia.

The purpose of the journal is to promote scientific exchange and cooperation between Russian and foreign political scientists.

The journal is intended for the publication of the results of fundamental and applied scientific research. Thematic focus of the journal is reflected in the following permanent headings: "History and philosophy of politics," "Political institutions, processes and technologies," "Political regionalism and ethno-politics," "Political culture and ideologies," "Political problems of international relations and globalization."

Format of publications: scientific articles, reviews, scientific materials, materials of round tables, scientific reviews, scientific reports devoted to research problems in the field of politics and political science.

The Editorial Board and the editors of the journal in their activities are guided by the principles defined by VAK of Russia for scientific journals, including: presence of the institute of peer review for the expert quality assessment of scientific articles; information openness of the publications; availability and compliance with the rules and ethical standards for the submission of manuscripts by the authors.

The target audience of the journal is Russian and foreign specialists-political scientists, as well as graduate students and masters in the fields of political science, state and municipal management and international relations.

The journal strictly adheres to the international publishing standards and publication ethics identified in the COPE (Committee on Publication Ethics) document. http://publicationethics.org.

Full details of the journal and its editorial policy, requirements to the preparation and publication of articles, archive (issues since 2011) and additional information are available on the website: http://voprospolitolog.ru

E-mail address: voprospolitolog@yandex.ru 


\section{ТЕОРИЯ, ФИЛОСОФИЯ И ИСТОРИЯ ПОЛИТИКИ}

Аствацатурова М.A. «Северокавказское имагинарное»

в социальной сущностно-функциональной этике

политического управления

Грудина T.H. Константы религиозного и политического учения

С.Л. Франка: социально-философский анализ.

\section{ПОЛИТИЧЕСКИЕ ИНСТИТУТЫ, ПРОЦЕССЫ И ТЕХНОЛОГИИ}

Назаров А.Д., Назарова Е.А. Особенности интеграции

беспилотных летательных аппаратов в сферу гражданской авиации:

политико-правовые аспекты

Прончев Г.Б., Михайлов А.П. Подходы к изучению

и моделированию кланов как фактора политической системы .

Бродская Н.П. Искусственный интеллект: попытки применения

в социальном пространстве и проблемы адаптации.

Галиева С.И., Галиева Г.М. Оценка эффективности институциональной системы реализации государственной политики по профилактике преступности и меры по ее совершенствованию

Амиантова И.С. Факторы успеха партии «Новые люди»

в ходе региональных выборов 2020 г. в России

Maйcmam M.A. Эндогенный период в развитии российской

многопартийности (1991-1999 гг.): «апоритивный синдром»

By $\boldsymbol{T} \boldsymbol{x} \boldsymbol{u}$ Xыюнг. Праймериз как PR-инструмент мобилизации граждан

в рамках электорального процесса

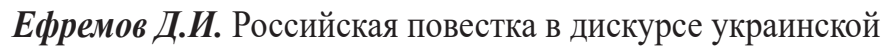
политической элиты: на примере президентских кампаний (2010-2019)

Аветисян A.C. Система политического менеджмента корпораций в общем цикле принятия и реализации стратегических решений

Голофаст A.B. Политические процессы

в цифровую эпоху: междисциплинарный синтез

Ильин И.С. Взаимодействие государственной власти

Российской Федерации и Русской Православной церкви

в условиях усложнения эпидемиологической обстановки в мире

Зверева М.В., Новикова А.В., Попов С.И. Проблемы государственного регулирования социально-экономического развития и управления в московской агломерации. Пути решения

Махрамов У.Ш. Коммуникативная тактика

и стратегия справедливости общества. 
Агурова А.А., Тихонова А.В. Анализ активности

политических партий на платформе социальных сетей

в контексте предвыборной кампании 2021 года.

ПОЛИТИЧЕСКАЯ ПСИХОЛОГИЯ, КУЛЬТУРА И ИДЕОЛОГИИ

Сабирова Н.С. Гражданское общество

как аспект современной политической культуры России

Зубова О.Г. Особенности ценностной структуры молодежи

в современном российском обществе

Имомов Э.И. Духовная среда:

содержание, аспекты и основы формирования

ПОЛИТИЧЕСКАЯ КОНФЛИКТОЛОГИЯ

Зазнаев О.И., Сидоров В.В. Взаимосвязь форм государственного

правления и этнических конфликтов: статистический анализ

\section{МЕЖДУНАРОДНЫЕ ОТНОШЕНИЯ И МИРОВАЯ ПОЛИТИКА}

Магадиев М.Ф. Санкционная политика ведущих стран мира

в отношении Российской Федерации: угрозы и основные направления противодействия

Шалыгина Н.В., Снежкова И.А. Молодежь как перспективный ресурс российско-белорусской интеграции..

Равочкин H.H. Анализ причин неудачного заимствования

передового политико-правового институционального опыта

странами Африки и Латинской Америки

Аниськевич Н.C. Чили и Тихоокеанский альянс: новые векторы взаимодействия 3268

Зубов В.В., Родионова М.Е., Ульянов Д.В. Перспективы российско-американских отношений в контексте политики, проводимой администрацией президента Трампа, и ее влияния на преобразование американской конъюнктуры. 3276

Данюк Н.С., Сенокоп Я.С. «Цветные революции» как инструмент гибридных технологий во внешней политике 3288

Капитонов А.A. Смена парадигмы развития:

экологический фактор в прошлом, настоящем и будущем 3298

Сарсембаев Н.B. Развитие сирийского конфликта: от требований демократических преобразований к религиозно-мотивированному террору 
Гомелаури А.C. К вопросу восприятия феномена «мягкой силы» в контексте российской внешней политики 3316

Ло Линянь. Феномен глобального лидерства в мировой политике 3324

Шоимов А. Основные направления политики взаимодействия гражданского общества и государства на новом этапе национального развития Узбекистана.

Юдин H.O. Культурная политика Газпрома: внутриполитические и внешнеполитические аспекты.

Никуикин А.Б. Особенности электронного участия в Пиратской партии Германии 3348

Семибоков Д.А. Актуальные вопросы устойчивости политических систем непризнанных государств

\section{СТУДЕНЧЕСКАЯ НАУКА}

Пекпаева М.А. Информационное общество: современные реалии и проблемы развития. 3364

Гришин B.O. Развитие железнодорожного пассажирского транспорта Московской области: проблемы и перспективы социально-политического проектирования ..

\section{КОНФЕРЕНЦИИ}

Жигульская Д.В. Международная научно-практическая конференция молодых ученых online «Этно-социокультурные процессы в странах Азии и Африки: проблема идентичности»

НАШИ АВТОРЫ 3390 


\section{АКТУАЛЬНЫЕ ВОПРОСЫ УСТОЙЧИВОСТИ ПОЛИТИЧЕСКИХ СИСТЕМ НЕПРИЗНАННЫХ ГОСУДАРСТВ}

В статье рассматриваются основные проблемы, связанные с устойчивостью политических систем непризнанных республик. Помимо описания теоретического аспекта, в статье приводятся внутренние и внешние факторы, определяюшие уникальность непризнанных государств постсоветского пространства. Представлена роль этнополитических конфликтов в формировании непризнанных государств.

Существование различных подходов к пониманию проблемы непризнанных государств выявляют существующчие противоречия и дают основу для научной дискуссии.

Ключевые слова: политические системы, непризнанные государства, непризнанные республики, этнополитические конфликты.

Актуальная политическая обстановка выдвигает для науки необходимость изучения политических систем непризнанных государств. Это, в свою очередь, позволяет определить не только причины возникновения данных территориальных образований, но и дает возможность анализировать возможные последствия действующего вектора внешней государственной политики других государств. В данном контексте нельзя также оставить без внимания проблематику, связанную с нестабильностью политических систем современных непризнанных республик.

Однако прежде чем перейти непосредственно к актуальным особенностям устойчивости политических систем непризнанных государств, стоит взглянуть на истоки возникновения указанной проблематики.

По мнению А.Н. Сквозникова [9. С. 8], огромное влияние на формирование политических систем непризнанных республик постсоветского периода оказало падение Ялтинско-Потсдамской системы международных отношений вместе с ее системой геополитических сдержек и противовесов, обеспечивавшейся существованием двух полюсов силы. Начиная с этого момента, наблюдалось резкое падение авторитета $\mathrm{OOH}$, ее способности оказывать реальное влияние на возникающие повсеместно этнополитические конфликты. 
Ключевые особенности появления непризнанных государств описывал философ и политолог Д. Голдейнус [10. С. 36]:

1. Первой характеристикой непризнанного государства является особенность его возникновения, а именно то, что оно происходит в одностороннем порядке, т.е. против воли центральных управленческих структур, с чьим сопротивлением им приходится столкнуться (чаще всего с вооруженным). Подобный процесс носит название сецессии.

2. Для достижения независимости необходимо существование организованного сообщества внутри определенной территории, стремящегося к автономии, а также имеющего своих политических лидеров, настроенных на отделение и организующих данный процесс.

3. Еще одним признаком является мотив обособления. Чаще всего им является стремление к независимости из-за резкого несогласия с существующим на территории государства порядком вещей. Однако оно должно быть настолько сильным, что заставит население предпочитать борьбу за независимость спокойной жизни. К мотиву можно отнести так же религиозные и этнические элементы.

4. В качестве дополнительного фактора автором указывается расчет времени. Сепаратисты могут ожидать слабости центрального аппарата прежде, чем начать борьбу за обособление.

Кроме того, Д. Голейнус отмечает, что стремление к независимости не всегда является целью для организаторов процесса обособления. Некоторые сообщества стремятся отделиться от одного государства, чтобы присоединиться к другому.

Говоря о бывших советских республиках с территориальными проблемами, А.Г. Большаков отмечает, что их до сих пор можно трактовать вовсе как так называемые «несостоявшиеся государства» с наличием ослабленного государственно-управленческого аппарата и коллапсирующей экономикой. Это можно объяснить тем, что распад СССР уже проходил в условиях общего экономического, внешнеполитического и демографического кризиса, оставив большинству из новообразованных государств целый ряд нерешенных проблем в этих сферах [6. С. 64]. Несмотря на то, что данные положения прямо не относятся к вопросу формирования политических систем именно непризнанных республик, они во многом характеризуют ситуацию их возникновения.

Кроме того, в основе проблемы политических систем непризнанных государств А.Г. Большаков видел проблему конкурирующих принципов в международном праве: принципа права народов на самоопределение, а также принципа нерушимости государственных границ и территориальной целостности государств [5. С. 84].

Некоторые исследователи, в частности А.Р. Аклаев, выдвигают идею, что все непризнанные государства постсоветского пространства возникли в результате этнополитических конфликтов [2. С. 25]. 
В.Ф. Пряхин отмечает, что причину подобных конфликтов следует искать в исторической плоскости, т.к. большинство непризнанных государств так или иначе опирались либо на уже существующее административное деление, сложившееся с течением времени, либо на исторические административно-территориальные единицы, существовавшие в прошлом. Именно на подобной основе формировались границы самопровозглашенных территорий [8. С. 214].

В свою очередь С.М. Маркедонов отмечает, что все конфликты на территории бывшего СССР имеют под собой насквозь историчную идеологическую основу и подоплеку [7. С. 120].

Говоря об особенностях политических систем с точки зрения политического устройства непризнанных государств постсоветского пространства, необходимо отметить, что подавляющее большинство их правительств позиционирует себя как приверженных демократии и развитию общественных гражданских институтов вкупе с уважением прав человека. Поэтому, большинство непризнанных государств в своих политических системах стремится к созданию «демократического фасада» для удовлетворения мировой общественности [11. С. 58].

Стоит также отметить неуступчивость правительств непризнанных политико-территориальных образований, ввиду их уверенности в том, что только независимость является единственным выходом из конфликтной ситуации.

Это можно объяснить несколькими причинами:

1) физический контроль занимаемой территории при возможном наличии территориальных претензий к бывшей метрополии (суверенитет Абхазии до 2008 года не распространялся на территорию Кодорского ущелья и Галльского района);

2) поддержка большинства населения, выраженная проведением выборов или референдумов (например, в Южной Осетии проходили референдумы о независимости в 1992 г., выборе государственного языка в 2011 г., а также планировался референдум о присоединении к Российской Федерации в 2014 г.), которую уже не так просто получить, т.к. с момента провозглашения независимости прошло достаточно времени, и первоначальный эмоциональный запал сошел на нет;

3) сильный государственный строй, выраженный главенствующей ролью президента/национального лидера, отсутствием политического плюрализма и персонификацией внешней и внутренней политики;

4) апеллирование к исторической справедливости, иначе говоря, к вопросам освобождения этноса или территории, достижению независимости и суверенитета как высшей точки исторического развития.

Г.И. Авцинова и А.И. Новицкая отмечают также частую слабость группировок, пришедших к власти в самопровозглашенных республиках, выраженную прежде всего отсутствием управленческого опыта [1. С. 70]. 
Подобная ситуация в управляющем аппарате непризнанных республик сказывается на устойчивости всей политической системы в целом. Самопровозглашенные лидеры не согласятся на делегирование им каких бы то ни было полномочий в условиях сохранения территориальной целостности метрополии, что в итоге может привести к дальнейшему нагнетанию обстановки и силовому решению конфликта.

Это, в свою очередь, демонстрирует еще один внутренний фактор, влияющий на стабильность политической системы непризнанного государства на постсоветском пространстве. Он представляется в виде постоянного наличия угрозы возобновления военных действий, вынуждающего правительства самопровозглашенных республик мобилизовать большинство ресурсов на защиту и оборону, что в свою очередь рискует вылиться в излишнюю милитаризацию населения, формирование незаконных группировок и рост криминальной активности.

Кроме того, 3.3. Бахтуридзе и М.Л. Лагутина отмечают еще одну особенность современных политических систем непризнанных государств. По их мнению, ей является этническая идентичность, связанная с территориальным аспектом, которая пришла на смену «идеологическому вакууму» гражданской идентичности на постсоветском пространстве [4. С. 125]. Лидеры самопровозглашенных республик акцентируют внимание как мирового сообщества, так и собственного населения именно на этом показателе государственности, оправдывая необходимость провозглашения независимости.

Совокупность внешних факторов, влияющих на сохраняющееся нестабильное состояние политических систем непризнанных республик, также зачастую рассматривается отдельно.

Прежде всего, это негативное влияние самих стран, подверженных сецессии: Молдавии, Грузии, Азербайджана и Украины. Их правительства не смогли привлечь ни население самопровозглашенных республик, ни их руководство возможными выгодами от восстановления разорванных политических и экономических связей, возможными реинтеграционными планами с равной выгодой для обеих сторон. Относительно возможного возобновления экономических отношений между самопровозглашенной территорией и государством-метрополией следует отметить определенную Д. Линчем дилемму, стоящую перед правительством последнего [12. С. 844]. С одной стороны, можно возобновить подобные связи, как это сделало молдавское правительство в отношении Приднестровья, однако это не способствует ни политической разрядке между сторонами, ни прекращению приграничных таможенных стычек. С другой стороны, можно объявить экономическую блокаду сепаратистским регионам, как это сделали грузинское и азербайджанское правительства. При этом политическая элита государств-метрополий чаще настроена либо на силовое разрешение вопроса с насильственным включением сепаратистских областей обратно 
в состав государства, либо на достижение в ходе переговоров соглашений, ставящих позиции противоборствующих сторон в неравное положение. Становится очевидно, что без какой-либо поддержки извне, будь то наличие государства-покровителя или же помощь прочих негосударственных акторов, дальнейшее развитие самопровозглашенных территорий невозможно, равно как и их возможное признание мировым сообществом в будущем.

По мнению Б.М. Ашавского и Е.В. Ананьевой, зачастую под заинтересованностью внешних сил изменить или законсервировать статус непризнанного политико-территориального образования скрывается проблема наличия страны-покровителя или отсутствия таковой. Большинство самопровозглашенных территорий постсоветского пространства так или иначе имеют государство, косвенно заинтересованное в существовании подобной самопровозглашенной территории и старающееся открыто или втайне поддерживать его существование [3. С. 54-55].

Несмотря на наличие целого ряда трудностей с определением понятийных и смысловых рамок проблемы непризнанных государств в целом, можно утверждать о наличии целого ряда характеристик, свойственных большинству самопровозглашенных государственных образований вне зависимости от их местоположения на политической карте мира. Они касаются, во многом, этнополитических конфликтов (их характера и результатов), непосредственно связанных с возникновением непризнанных государств, наличия схожего процесса формирования государственности и политикоэкономического контроля над занимаемой территорией. Конфликтный фактор возникновения непризнанных государств является доминирующим, оказывая решающее влияние на политико-идеологическую основу политико-территориальных образований со спорным статусом. Внешне- и внутриполитическое функционирование последних, а также их перспектива возможного международного признания напрямую зависит от наличия государства-покровителя или прочего международного актора, косвенно заинтересованного в существовании подобных образований.

Непризнанные государства постсоветского пространства имеют ряд специфических характеристик, свойственных данному региону и определяющих их образование и функционирование, которые можно условно поделить на внутренние и внешние. Вся совокупность внутренних особенностей заключается в сильной роли историко-идеологической составляющей государственной политики данных самопровозглашенных образований, выливающейся в неуступчивость их правительств, милитаризации общества при растущей тенденции к авторитарному управлению при наличии внешнего «демократического фасада», а также потенциально нестабильную внутриполитическую обстановку. Внешними особенностями непризнанных государств постсоветского пространства являются влияние государств-метрополий, которое обычно имеет негативный характер, заинтересованность 
сторонних держав в развитии ситуации, а также степень вовлеченности Российской Федерации в происходящие события ввиду очевидного стремления нашей страны к сохранению геополитического позиции в регионе. Кроме того, можно говорить о наличии доминирующего конфликтного фактора образования непризнанных государств, характеризующегося дифференциацией и спецификой в каждом конкретном случае. В этом отношении ни в коем случае нельзя упускать из виду риск очередной эскалации замороженных конфликтов, которая более чем вероятна в условиях вышеописанных изменений мирополитической конъюктуры. Как было упомянуто, немало подобных тлеющих конфликтов находится на территории постсоветского пространства.

На примере этнополитических конфликтов, ни один из которых не является разрешенным полноценно, можно утверждать о вялотекущем характере противостояния после заключения в какой-либо форме перемирия между воюющими сторонами. Подобная ситуация демонстрирует нестабильное состояние политических систем непризнанных государств и в целом указывает на особенности их внутриполитического устройства.

\section{БИБЛИОГРАФИЧЕСКИЙ СПИСОК:}

1. Авцүинова Г.И., Новицккая А.А. Особенности функционирования непризнанных государств // Наука и современность. 2015. № 3.

2. Аклаев A.P. Этнополитическая конфликтология: анализ и менеджмент. М.: Дело, 2005.

3. Ашавский Б.М., Ананьева Е.В. Проблема признания государств // Международная жизнь. Ноябрь 2009. № 11.

4. Бахтуридзе 3.3., Лагутина М.Л. Особенности формирования системы международных отношений на постсоветском пространстве: непризнанные государства // Современные проблемы науки и образования. 2015. № 1-1.

5. Большаков А.Г. Непризнанные государства европейской периферии и пограничья // Международные процессы. Сентябрь-декабрь 2007. № 3 (15).

6. Большаков А.Г. Российский интеграционный проект и несостоявшиеся государства постсоветского пространства // Вестник ВГУ. Серия: История. Политология. Социология. 2014. № 4.

7. Маркедонов C.M. Турбулентная Евразия: межэтнические, гражданские конфликты, ксенофобия в новых независимых государствах постсоветского пространства. М.: Московское бюро по правам человека, Academia, 2010.

8. Пряхин В.Ф. Региональные конфликты на постсоветском пространстве (Абхазия, Южная Осетия, Нагорный Карабах, Приднестровье, Таджикистан). М.: ООО «Издательство ГНОМ и Д», 2002.

9. Сквозников А.Н. Феномен непризнанных и частично признанных государств и особенности их правосубъектности // Вестник Самарской гуманитарной академии. Серия: Право. 2011. № 2. 
10. Deon Geldenhuys. Contested States in World Politics. Palgrave Macmillan, 2009.

11. Caspersen N., Stansfi eld G. Unrecognized States in the international system. Routledge, 2010.

12. Lynch D. Separatist states and Post-Soviet Conflicts // International Affairs. 2002. Vol. 78. № 4.

\author{
D.A. SEMIBOKOV \\ Post-graduate student of Lomonosov \\ Moscow State University, \\ Moscow, Russia
}

\title{
ACTUAL ISSUES OF STABILITY POLITICAL SYSTEMS OF UNRECOGNIZED STATES
}

The article presents the main problems associated with the stability of the political systems of the unrecognized republics. In addition to describing the theoretical position, the article contains internal and external factors that determine the uniqueness of the unrecognized states of the post-Soviet space. The role of ethnopolitical conflicts in the formation of unrecognized states is presented.

The existence of different approaches to understanding the problem of unrecognized states reveal contradictions and provide a basis for scientific discussion.

Key words: political systems, unrecognized states, unrecognized republics, ethnopolitical conflicts. 